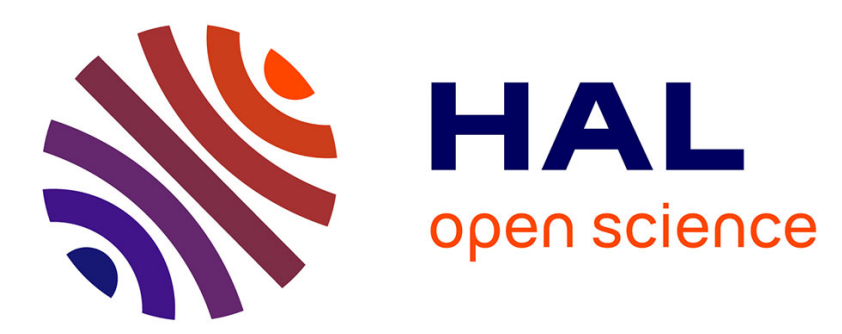

\title{
ANISOTROPIC INTERACTIONS BETWEEN MBBA AND SURFACE-TREATED SUBSTRATES
}

\author{
S. Naemura
}

\section{To cite this version:}

S. Naemura. ANISOTROPIC INTERACTIONS BETWEEN MBBA AND SURFACETREATED SUBSTRATES. Journal de Physique Colloques, 1979, 40 (C3), pp.C3-514-C3-518. 10.1051/jphyscol:19793103 . jpa-00218704

\section{HAL Id: jpa-00218704 https://hal.science/jpa-00218704}

Submitted on 1 Jan 1979

HAL is a multi-disciplinary open access archive for the deposit and dissemination of scientific research documents, whether they are published or not. The documents may come from teaching and research institutions in France or abroad, or from public or private research centers.
L'archive ouverte pluridisciplinaire HAL, est destinée au dépôt et à la diffusion de documents scientifiques de niveau recherche, publiés ou non, émanant des établissements d'enseignement et de recherche français ou étrangers, des laboratoires publics ou privés. 


\title{
ANISOTROPIC INTERACTIONS BETWEEN MBBA AND SURFACE-TREATED SUBSTRATES
}

\author{
S. NAEMURA \\ Central Research Laboratories, Nippon Electric Co., Ltd. \\ 4-1-1 Miyazaki, Takatsu-ku, Kawasaki 213, Japan
}

\begin{abstract}
Résumé. - Nous avons déterminé la direction de l'axe facile du directeur et son énergie d'ancrage $B_{\theta}$ aux interfaces MBBA-substrat solide [traité avec des agents tensio-actifs], par la méthode de la transition de Freedericksz. Les résultats expérimentaux indiquent que les interactions stériques, dispersives et polaires sont importantes dans la détermination de l'orientation des molécules sur les lames. Nous avons trouvé des valeurs de $B_{\theta}$ assez faibles et estimons l'anisotropie de tension superficielle du MBBA à environ $10^{-2} \mathrm{dyn} / \mathrm{cm}$.
\end{abstract}

Abstract. - Easy axis $\Theta$ and anchoring strength coefficient $B_{\theta}$ were measured on the interfaces between MBBA and substrates with various surfactants layers, by using wall effects on the Freedericksz transition. Experimental results indicate that steric, dispersive and polar interactions play individual roles in the molecular orienting forces of surface-treated substrates. $B_{\theta}$ values were found to be rather small. MBBA surface tension anisotropy was estimated to be of the order of $10^{-2} \mathrm{dyn} / \mathrm{cm}$.

1. Introduction. - Several substrates with surfactant layers exert an orienting effect on liquid crystal (LC) molecules. The surface orientation of LC molecules is characterized using the easy axis $(\Theta, \Phi)$ and anchoring strength coefficients $B_{\theta}$ and $B_{\varphi}$. It is known that LC molecules align homeotropically $\left(\Theta=0^{\circ}\right)$ on the surfactant layer with a long alkyl chain, and the polar angle of the easy axis $\Theta$ increases as the surfactant chain length decreases [1]. Also, $B_{\theta}$ values are found to be very small in several cases $[1,2]$. However, anchoring strength measurement was rather difficult and experimental data regarding $B$ values were quite limited. This is one of the reason why there is poor understanding of mechanisms for molecular orientation on substrates. Recently, a new method has been developed to measure anisotropic interfacial interactions between nematic LC molecules and substrates by using wall effects on the Freedericksz transition [3]. This paper reports measured $\Theta$ and $B_{\theta}$ values between MBBA (p-methoxybenzylidene- $\mathrm{p}^{\prime}$ butylaniline) and various substrates with serial surfactants layers. It also presents some consideration on molecular orienting forces.

2. Theoretical. - Interfacial interaction energy per unit area $W_{\mathrm{s}}$ is represented using polar angle $\theta_{0}$ and azimuthal angle $\varphi_{0}$ for a director at the interface (Fig. 1). Here, conical configuration is considered under the $\partial \theta_{0} / \partial x=\partial \theta_{0} / \partial y=0$ condition. Then $W_{\mathrm{s}}$ is modeled into the form

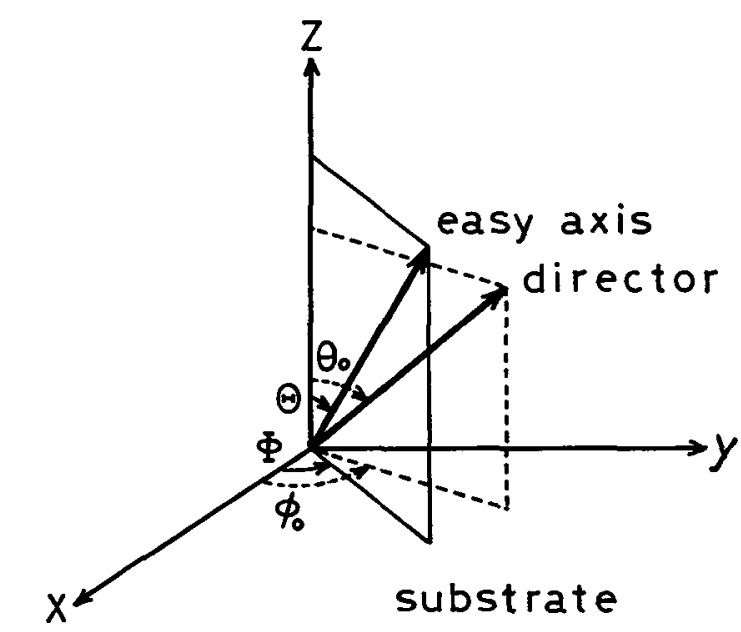

FIG. 1. - Interface notations.

$W_{\mathrm{s}}=\frac{A}{2}+\frac{B_{\theta}}{2} \sin ^{2}\left(\theta_{0}-\Theta\right)+\frac{B_{\varphi}}{2} \int \sin ^{2}\left(\varphi_{0}-\Phi\right) \mathrm{d} S$,

where $A, B_{\theta}$ and $B_{\varphi}$ are anchoring strength coefficients, $\Theta$ and $\Phi$ are easy axis components and $\int \mathrm{d} S$ means the surface integral for unit area. In case of homeotropic alignment, the third term is omitted. Consider a simple case where the third term can be neglected. Consider a nematic LC layer with thickness $l$, sandwiched between two parallel substrates with the 
same boundary condition. The director deformation under magnetic field $H$ parallel to the substrate is derived from the condition that the total free energy per unit area director dependent terms

$$
\begin{aligned}
G_{\theta}= & 2\left(\frac{B_{\theta}}{2}\right) \sin ^{2}\left(\theta_{0}-\Theta\right)+ \\
& +\frac{1}{2} \int_{-l / 2}^{l / 2}\left(K_{11} \sin ^{2} \theta+K_{33} \cos ^{2} \theta\right)\left(\frac{\mathrm{d} \theta}{\mathrm{d} z}\right)^{2} \mathrm{~d} z \\
& -\frac{1}{2} \int_{-l / 2}^{l / 2} \chi a H^{2} \sin ^{2} \theta \mathrm{d} z
\end{aligned}
$$

are minimum for $\theta$, where $K_{11}$ and $K_{33}$ are Frank elastic constants for splay and bend respectively and $\chi a$ is magnetic anisotropy. Equilibrium director deformation computation under the magnetic field shows that threshold magnetic fields $H_{\mathfrak{c}}^{\prime}$ depend on both $\Theta$ and $B_{\theta}$ [3]. These relations enable $B_{\theta}$ evaluation from measured $\Theta$ and $H_{c}^{\prime}$.

3. Experimental. - Experiments were accomplished using MBBA in the nematic phase. The surfactant layer was deposited by dipping a substrate in a surfactant solution. Homologous series of n-alkyl trimethyl ammonium salts and n-alkyl amines as well as some other cationic, nonionic and amphoteric surfactants were examined. The magneto-capacitance method was used to measure $\Theta$ and $H_{\mathrm{c}}^{\prime}$ for $\mathrm{In}_{2} \mathrm{O}_{3}$ evaporated glass substrates. The total reflection method was used for glass substrates. Measurements were performed for various thickness MBBA layers. $l$ values were determined carefully by using capacitance, optical interference and microscopic focusing measurements together. Measuring procedure details were reported in a previous letter [3].

4. Results. - A summary of experimental results is given in table I. Surfactants with long alkyl chain ( $n \gtrsim 10, n$ is the number of carbon atoms in the alkyl chain) promote MBBA homeotropic alignment $\left(\Theta=0^{\circ}\right)$. In case of n-alkyl amines, $\Theta=3^{\circ}$ was obtained even for $n=10$ and 12 . We used eq. (2) to approximately evaluate $B_{\theta}$ from $H_{\mathrm{c}}^{\prime}$ even for $\Theta \lesssim 5^{\circ}$, when $\varphi$-dependent term has some contributions to the total free energy, although eq. (2) was

TABLE I

Easy axes $\Theta$ and anchoring strength coefficients $B_{\theta}$ on interfaces between $M B B A$ and substrates with various surfactants

(a) $\mathrm{In}_{2} \mathrm{O}_{3}$ evaporated glass substrate.

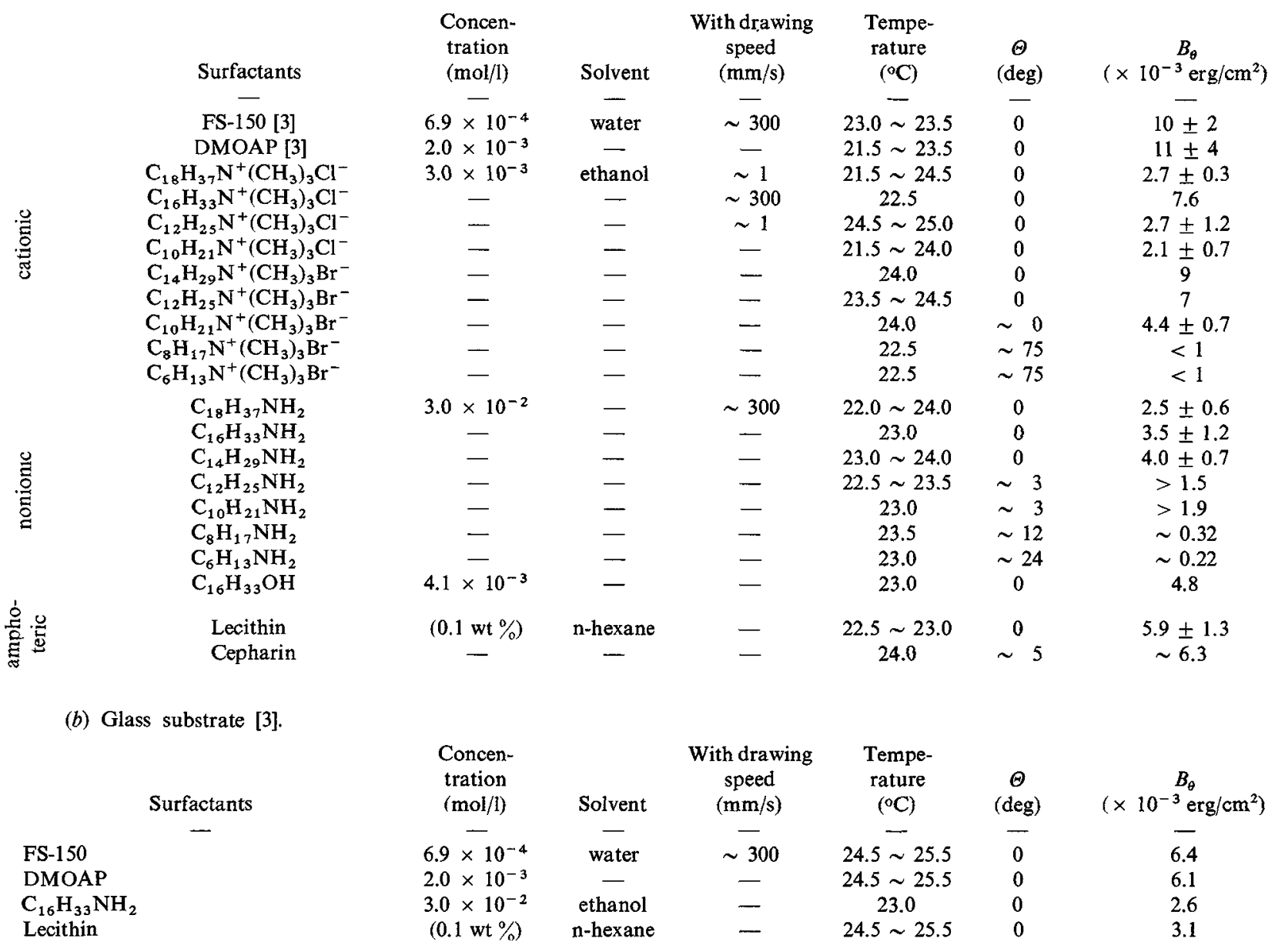


rigorously derived by neglecting the $\varphi$-dependent term. The results indicate that $B_{\theta}$ depends on the surfactants chain length. $B_{\theta}$-vs- $n$ relationships are given in figure 2. Figure 2 shows that $B_{\theta}$ depends

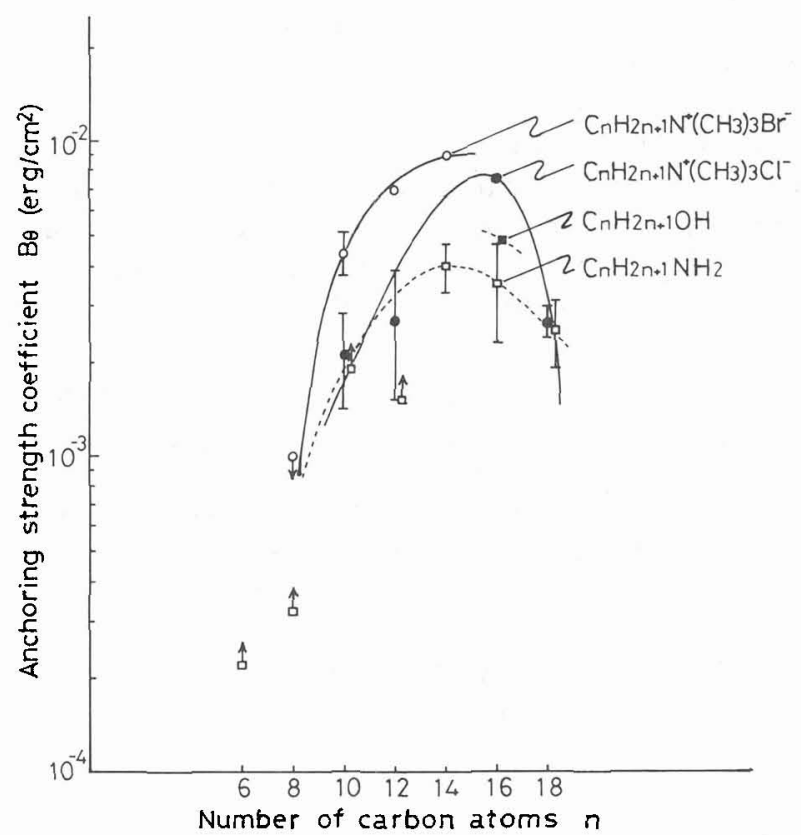

FIG. 2. - Relations between anchoring strength coefficient $B_{\theta}$ and number of carbon atoms $n$ in surfactant alkyl chain.

also on the polar groups of the surfactants. Larger values of $B_{\theta}$ were obtained for cationic surfactants than for nonionic surfactants of the same chain length. Besides, $\boldsymbol{B}_{\boldsymbol{\theta}}$ 's for the insulating glass substrates are smaller than those for the $\operatorname{In}_{2} \mathrm{O}_{3}$ evaporated conductive substrates. In case of $n=8$ or $6, \Theta$ is larger and therefore $\varphi$-dependent interaction term takes part in molecular orienting forces. This brings about a conical configuration (Fig. 3). This configuration is strongly affected by the LC molecules flow. Polarized microscopic observation gives a director distribution drawing as shown in figure 3. Parallel dark lines in the LC flow direction ( $x$-axis) indicate $\partial \varphi / \partial x \simeq 0$. Their darkness becomes maximum under the cross-nicols condition, that means $\partial \varphi / \partial z=0$. $\partial \varphi / \partial y=2 \pi / c l$ ( $c$ is a constant) is obtained by the observation for a wedge cell. In case of larger $l$ values, $\partial \varphi / \partial y$ becomes nearly equal to zero and the configuration is something like a planar structure. Thermal treatment breaks the conical configuration. If the cell is heated above the nematic-isotropic transition temperature and then cooled slowly under a magnetic field perpendicular to the substrates, a different configuration is obtained. In this configuration, several regions of different $\varphi$ 's are divided by surface disclination lines and Néel type walls. $\theta=\Theta$ is assumed in a large part of the cell except in the vicinity of those defects, and $\Theta$ can be estimated by capacitance measurements. $\Theta=75^{\circ}$ was obtained for n-alkyl trimethyl ammonium bromides $(n=6,8)$. In
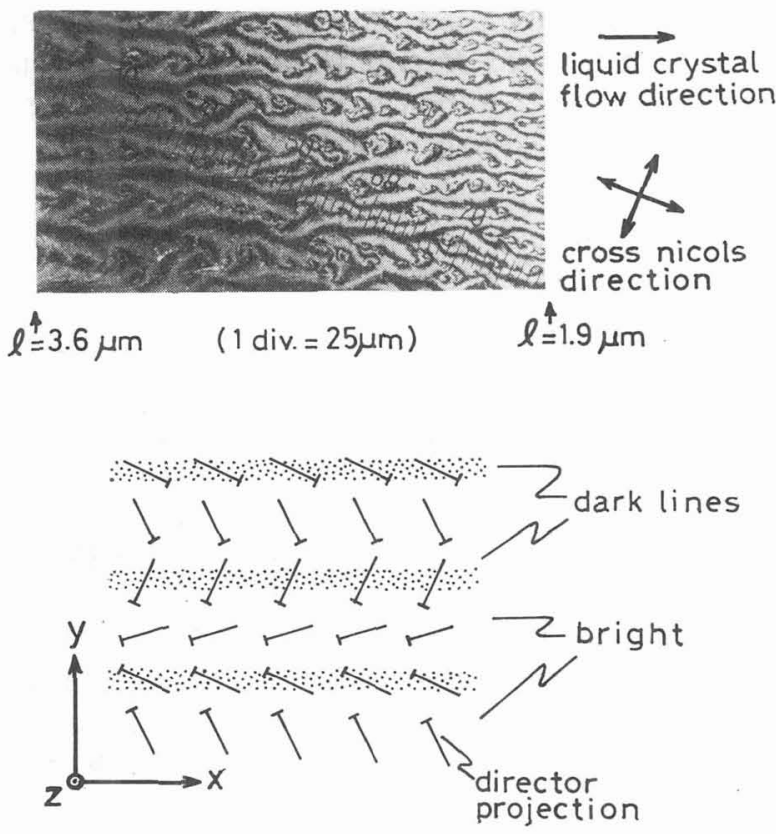

Fig. 3. - Polarized microscopic observation of conical configuration (wedge cell, $\mathrm{n}$-hexyl trimethyl ammonium bromide).

case of n-alkyl amines, $\Theta$ is about $12^{\circ}$ for $n=8$ and about $24^{\circ}$ for $n=6$. In this configuration, $B_{\theta}$ 's are estimated by the topological observation used in reference [1]. They are of the order of $10^{-4} \mathrm{erg} / \mathrm{cm}^{2}$.

5. Discussion. - The results presented in section 4 are summarized : $\Theta$ is zero (homeotropic alignment) for the long-chain surfactants and increases as chain length decreases. $B_{\theta}$ depends on both the hydrophobic chain and the hydrophilic group of the surfactants. That is, decreasing the chain length makes $B_{\theta}$ smaller, and $B_{\theta}$ 's for cationic surfactants are larger than those for nonionic surfactants of the same chain length. Also, substrate materials influence $B_{\theta}$. That is, for cationic surfactants, glass substrates reduce $B_{\theta}$ values by almost half, compared with $\mathrm{In}_{2} \mathrm{O}_{3}$ evaporated glass substrates. These results help in considering mechanisms of LC molecular orientation on substrates.

5.1 STERIC CONSIDERATION. - The relations between $\Theta$ and $n$ are interpreted as a result of steric effects. It is known that LC molecules align homeotropically when the alkyl chains of surfactants are perpendicular on the substrate, and align parallel when they are parallel on the substrate [4]. Therefore, it is considered that surfactant alkyl chains tend to align perpendicular if they are long enough. LC molecules lie parallel to the chains because of dispersive forces. Actually the long alkyl chains of surfactants were found to be orienting perpendicular on the substrate. Figure 4 shows reflective electron diffraction patterns for $\operatorname{In}_{2} \mathrm{O}_{3}$ evaporated substrates without surfactants $(a)$ and with n-tetradecyl trimethyl 

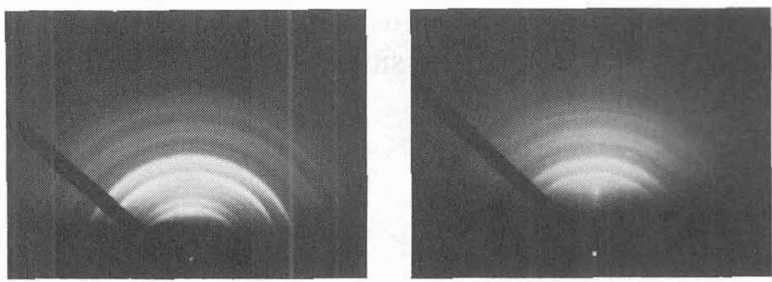

FIG. 4. - Reflective electron diffraction patterns. (a) $\ln _{2} \mathrm{O}_{3}$ evaporated glass surface. $(b)$ n-tetradecyl trimethyl ammonium bromide layer on $\mathrm{In}_{2} \mathrm{O}_{3}$ evaporated glass.

ammonium bromide layer $(b)$. Figure $4 b$ shows a vertical line of spots, which suggests a perpendicular orientation of alkyl chains on the substrate. Decreasing of $B_{\theta}$ for rather short-chain surfactants is considered to be the result of the dispersive force $n$-dependence.

5.2 Electrostatic CONSIDERATION. - The effects of the polar group of surfactants and the substrate materials on $B_{\theta}$ values suggest that polar interactions play several roles in the molecular orienting forces. According to J. E. Proust et al. [5], dipole-dipole interactions are dominant in the LC molecular alignment at a humid glass surface. The dipole-dipole interaction acts to orient MBBA molecules parallel on such a glass substrate. Actual alignment of MBBA on the surfactant layer with alkyl chains is, therefore, determined by a balance between polar and nonpolar (dispersive) forces. Dispersive forces are dominant in the interfacial interactions between LC molecules and the long-chain surfactant layer, and promote homeotropic alignment in cooperation with steric effects. Even in case of homeotropic alignment, polar interactions have latent effects on $B_{\theta}$ values.

5.3 Physicochemical CONSIDERATION. - Here alignment on a longchain surfactant layer is considered, where dispersive forces are dominant. In this case, the interfacial interaction energy is considered to be

$$
W_{\mathrm{s}}=\gamma_{\mathrm{s}}^{\mathrm{d}}+\gamma_{\mathrm{L}}^{\mathrm{d}}(\theta)-W_{\mathrm{a}}^{\mathrm{d}}(\theta),
$$

where $\gamma_{s}^{\mathrm{d}}$ and $\gamma_{\mathrm{L}}^{\mathrm{d}}(\theta)$ represent dispersive terms for substrate and liquid crystal surface tension, respectively. Also, $W_{\mathrm{a}}^{\mathrm{d}}(\theta)$ represents the dispersive term of adhesion energy. According to F. M. Fowkes [6], we can write

$$
\begin{gathered}
W_{\mathrm{a}}^{d}(\theta)=2 \sqrt{\gamma_{\mathrm{s}}^{d} \cdot \gamma_{\mathrm{L}}^{d}(\theta)}, \\
\gamma_{\mathrm{s}}^{d} \cong \gamma_{\mathrm{c}},
\end{gathered}
$$

where $\gamma_{c}$ is the critical surface tension of a substrate. In case of $\Theta=0^{\circ}$, by inserting eq.'s (1), (4) and (5) into eq. (3), we can get

$$
\frac{A}{2}+\frac{B_{\theta}}{2} \sin ^{2} \theta=\gamma_{\mathrm{c}}+\gamma_{\mathrm{L}}^{d}(\theta)-2 \sqrt{\gamma_{\mathrm{c}} \cdot \gamma_{\mathrm{L}}^{d}(\theta)},
$$

that is,

$$
\frac{B_{\theta}}{2}=\gamma_{\mathrm{L}}^{d}\left(\frac{\pi}{2}\right)-\gamma_{\mathrm{L}}^{d}(0)-2 \sqrt{\gamma_{\mathrm{c}}}\left(\sqrt{\gamma_{\mathrm{L}}^{d}\left(\frac{\pi}{2}\right)}-\sqrt{\gamma_{\mathrm{L}}^{d}(0)}\right)_{(7)} \text {. }
$$

Measured $\gamma_{\mathrm{c}}$ values for substrates with n-alkyl trimethyl ammonium bromide layers by the contact angle method are shown in figure 5 . Using the assumption of $\gamma_{\mathrm{L}}^{d}(0)<\gamma_{\mathrm{L}}^{d}(\theta)<\gamma_{\mathrm{L}}^{d}(\pi / 2), \Theta=0^{\circ}$ is obtained in case of $\gamma_{c}<\gamma_{L}^{d}(0)$ [1]. Therefore, it is possible that an approximate value $\gamma_{\mathrm{L}}^{d}(0) \cong 26 \mathrm{dyn} / \mathrm{cm}$ can be attained, from figure 5. By using $B_{\theta}$ and $\gamma_{\mathrm{c}}$ of n-alkyl

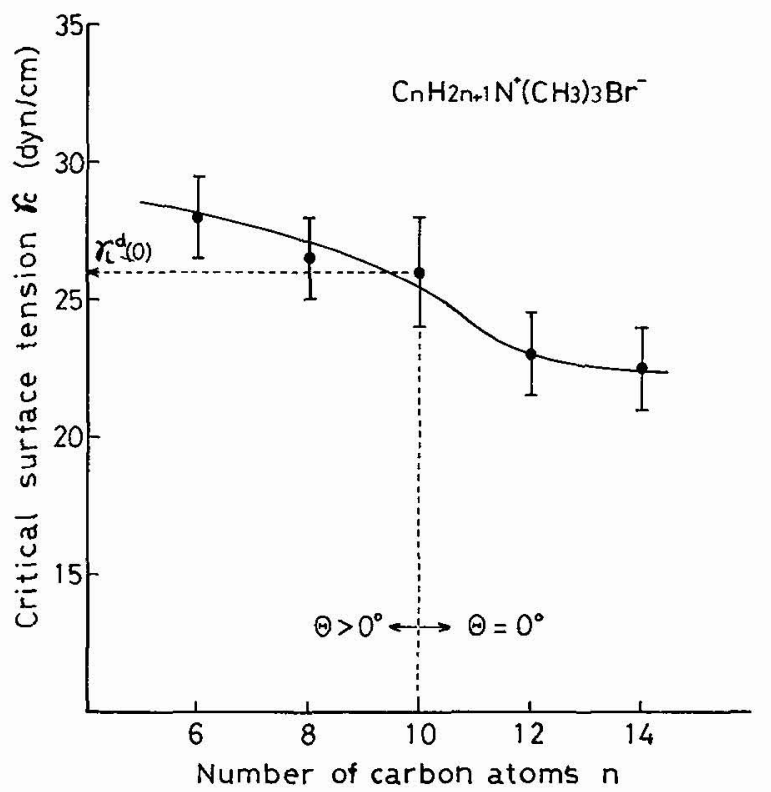

FIG. 5. - Critical surface tension for substrates with n-alkyl trimethyl ammonium bromide layers.

trimethyl ammonium bromide layers $(n=12,14)$. a $\gamma_{L}^{d}(\pi / 2)$ value is obtained from eq. (7) which gives the MBBA surface tension anisotropy

$$
\gamma_{\mathrm{L}}^{d}\left(\frac{\pi}{2}\right)-\gamma_{\mathrm{L}}^{d}(0)=(4.5 \pm 1.3) 10^{-2} \mathrm{dyn} / \mathrm{cm} .
$$

Despite rough measurements of $\gamma_{c}$ values, the surface tension anisotropy of liquid crystals is very small [7].

As a summary, $\Theta-\nu s-n$ relationships and electron diffraction observation suggest steric effects in mechanisms for molecular orientation. $n$-dependences of $B_{\theta}$ indicate that dispersive interactions play several roles in molecular orienting forces, and also polar interactions contribution is suggested by the results that $B_{\theta}$ is affected by both surfactant polar groups and substrate materials. The anisotropic anchoring strength of the surfactant layer with n-alkyl chain was found to be not so strong. Also, the surface tension anisotropy of MBBA was estimated to be rather small. 
6. Acknowledgments. - The author wishes to thank Dr. F. Saito for encouragement and many helpful discussions, C. Tani, F. Ogawa and T. Ueno for their helpful discussions, and Dr. I. Matsui for photographing and discussing reflective electron diffraction patterns.

\section{References}

[1] Porte, G., J. Physique 37 (1976) 1245.

[2] Ryschenkow, G. and Kleman, M., J. Chem. Phys. 64 (1976) 404.

[3] Naemura, S., To be published in Appl. Phys. Lett. 33 (1978) 1.

[4] Proust, J. E., Ter-Minassian-Saraga, L. and Guyon, E., Solid State Commun. 11 (1972) 1227.
[5] Proust, J. E. and Ter-Minassian-Saraga, L., J. Physique Colloq. 36 (1975) C1-77.

[6] Fowkes, F. M., Adv. Chem. Series 43 (1964) 99.

[7] Proust, J. E., Perez, E. and Ter-Minassian-Saraga, L., Colloid and Polymer Sci. 254 (1976) 672. 